DE-FG26-97FT34161--02

\title{
Development and Testing of a Ceria-Zirconia Toughened Alumina Prototype Filter Element Made of Reticulated Ceramic Foam Coated with a Ceramic Membrane Acting as Barrier Filter for Fly Ash
}

R\&D Director and Vice President: Kenneth R. Butcher

Principal Authors: Guilio A. Rossi, Kenneth R. Butcher and Stacia M. Wagner

FINAL REPORT

Submitted February 19, 1999

SELEE CORPORATION

700 Shepherd Street

Hendersonville, NC 28792 


\section{DISCLAIMER}

This report was prepared as an account of work sponsored by an agency of the United States Government. Neither the United States Government nor any agency thereof, nor any of their employees, makes any warranty, express or implied, or assumes any legal liability or responsibility for the accuracy, completeness, or usefulness of any information, apparatus, product, or process disclosed, or represents that its use would not infringe privately owned rights. Reference herein to any specific commercial product, process, or service by trade name, trademark, manufacturer, or otherwise does not necessarily constitute or imply its endorsement, recommendation, or favoring by the United States Government or any agency thereof. The views and opinions of authors expressed herein do not necessarily state or reflect those of the United States Government or any agency thereof.

Available to the public from the National Technical Information Service, U.S. Department of Commerce, 5285 Port Royal Road, Springfield, VA 22161; phone orders accepted at (703)487-4650. 


\section{Table of Contents}

1. Executive Summary 4

2. Objectives 5

3. Background 6

4. Technical Approaches $\quad 7$

4.1. Foam Core Development 8

4.2. Membrane Development 10

4.3. Application of Membrane to Foam Core 11

4.5. Firing 11

4.6. Pressure Drop Testing 12

5. Characterization of Delivered Samples 12

6. Conclusions and Suggestions for Future Work 15 


\section{Executive Summary}

In order to achieve the goal of making an improved fly ash candle filter Selee hoped to bring together three components of its technology.

The Composition - This was a ceria zirconia toughened alumina developed in a previous grant from the Department of Energy ${ }^{1}$. The composition has excellent strength, including hot strength and reasonably good thermal shock resistance. In addition it has excellent resistance to the type of chemical attack that has proven to be the downfall of some other types of filters.

Reticulated Ceramic Foam Structure - This structure is the basis from most of Selee's products. Being an open structure, the core of the candle can be made from it providing structural continuity with very little resistance to air flow.

GPM Porous Ceramic Structure - Selee recently developed an alternate method of making a porous ceramic structure. This structure has cells of 100 - 150 microns with interconnecting windows of $10-20$ microns.

The concept was to make a candle with a foam core and a GPM membrane, both components being made from the ceria zirconia toughened alumina.

Six subscale filter elements were produced after experimenting with several production techniques. Fabrication problems included machining the core from foam, applying the membrane coating without flaws, and supporting the structure during the drying and firing process. Considerable progress would have to be made before attempting to produce full sized candles.

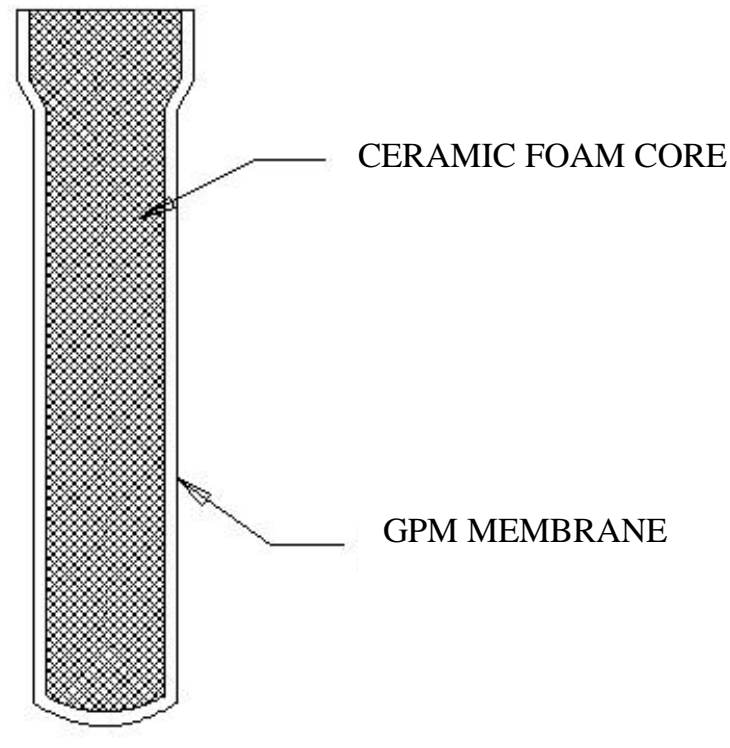




\section{Objectives}

The objective of this work was to fabricate subscale candle filters using a Ce-ZTA reticulated foam material. Specifically Selee fabricated $60 \mathrm{~mm}$ diameter cylinders with one closed end and one flanged end. Selee Corporation developed a small pore size (5-10 um) filtration membrane which was applied to the reticulated foam surface to provide a barrier filter surface.

The specific tasks to be performed were as follows:

Task 1 - Filter Element Development. To fabricate subscale filter elements from zirconia toughened alumina using the reticulated foam manufacturing process. The filter elements were required to meet dimensional tolerances specified by an appropriate filter system supplier. The subscale filter elements were fabricated with integral flanges and end caps, that is, with no glued joints.

Task 2-Membrane Development. To develop a small pore filtration membrane that is to be applied to the reticulated foam material. This membrane was to provide filtration characteristics that meet gas turbine requirements and pressure drop or permeability requirements specified by the filter system supplier.

Task 3 - Subscale Filter Element Fabrication. To fabricate six subscale filter elements with integral flanges and closed ends, as well as fine pore size filtration membranes. Three filters were to have a central clean gas channel, while three would have no central channel. The filters were to be provided to FETC for testing in laboratory systems or pilot scale exposure systems as appropriate. The candles were to meet dimensional tolerances as provided by filter system suppliers. 


\section{Background}

\section{Ceramic Filters for Coal Gas Filtration}

Ceramic barrier filters for the separation of fly ash from coal-derived hot gas exist in a variety of designs and ceramic compositions. Most of these filters work on the thruflow or cross-flow principle. The candle filter is the most common type of hot gas filter used in electric power plants, with typical dimensions of $6 \mathrm{~cm}$ diameter and $150 \mathrm{~cm}$ length. A cluster of candle filters is attached vertically to a plenum and several of these clusters are placed inside a large pressure vessel. The candle filter performs as a barrier that blocks the fly ash present in the dirty, coal-derived hot gas before it reaches the turbine. The ash laden filter is intermittently cleaned by air pulsing.

Although this design has been successful, occasionally candle filters break in operation due to thermo-mechanical stresses generated by thermal gradients and by the pulsing during cleaning. Due to the cantilever configuration and the high aspect ratio, the candle typically experiences fracture at the flange. A second issue, not resolved yet, is the ash bridging between adjacent candles, which can bring about premature failure and loss of efficiency.

Studies at the Southern Research Institute had shown that several candle filters manufactured by Schumacher, Refractron, Coors and others, tested at the Tidd and Karhula plants, failed mainly due to excessive creep, thermal shock and degradation of the bonding phase. A similar study, conducted by Mary Anne Alvin et al. of Westinghouse Electric Corp., had revealed several problems in both the oxide and nonoxide (i.e. $\mathrm{SiC}$ ) candles, such as oxidation, debonding and degradation of fibers and/or fiber coatings. After the analysis of these results, it was concluded that a more robust and reliable candle was needed. A candle was needed which had a higher fracture toughness, better stability in the harsh PFBC and IGCC environments and was not susceptible to catastrophic failure. Most importantly, the overall cost of manufacturing the filter needed to be reduced.

The development of a reticulated foam candle was investigated because it was thought to offer the following advantages when compared with existing filters:

High strength/weight ratio

High permeability to gas flow

Good thermal shock resistance

Good corrosion/erosion resistance

Fail-safe mechanism

Resistance to crack propagation

The high strength to weight ratio would offer the advantage over problems related to high temperature creep previously encountered. The high permeability is an obvious advantage when combined with the other required properties. The Selee foams, as 
generally fabricated is too coarse, cannot block the fly ash and therefore a thin ceramic membrane was developed and deposited on the outer surface of the candle. The thermal shock resistance depends mainly upon the foam density, cell size and composition. A membrane-coated foam possesses an inherent fail-safe mechanism, since the foam would become quickly clogged with ash if a crack formed on the surface, and consequently "turn itself off". The resistance to catastrophic crack propagation is due to the structure of a ceramic foam, where a crack can propagate through a strut and stop. In addition, the $\mathrm{Ce}-\mathrm{ZTA}$ possesses inherent toughness, since it contains transformable $\mathrm{t}-\mathrm{ZrO}_{2}$.

\section{Technical Approaches}

Three major components needed to be developed and integrated in order for the fabrication of an improved fly ash candle filter to be successful.

1) The composition of both the foam core and the porous membrane had to be optimized. Because the ceramic composition substantially shrinks during the sintering phase, it was necessary to tailor the foam core composition so that it would have similar thermal expansion rates and shrinkage as the membrane coating

2) The fabrication of a reticulated foam core with an open-cell structure and integral flanges and end caps while maintaining dimensional tolerances.

3) The development and application of a ceramic membrane using Selee's alternate method of creating porous ceramics (GPM technology) which would act as the barrier to fly ash and yet maintain low pressure drop at required flow rates.

Selee Corp. had received an SBIR Phase I and Phase II grant to develop and optimize a novel Ceria-zirconia toughened alumina (Ce-ZTA) ceramic foam with high strength, good thermal shock resistance and corrosion resistance. ${ }^{1}$ The composition was developed for use as a barrier filter in electric power plants with clean coal technology. The Ce-ZTA foam was tested in both Integrated Gasified Combined Cycle (IGCC) and Pressurized Fluid Bed Combustion (PFBC) simulated environments. The foam developed in Phase I was the strongest ceramic foam ever fabricated at Selee Corporation. The average strengths being as high as 1290psi at a density of $15 \%$ of theoretical density. The composition only showed a slight decrease in strength after thermal shock at $1000^{\circ} \mathrm{C}(93 \%$ strength retention). This material was tested against standard alumina and mullite foams of similar density and pore size and showed superior properties. The Ce-ZTA foam had a high $\mathrm{t}-\mathrm{ZrO}_{2}$ content $(>90 \%)$ and a uniform structure and had no significant decreases in strength when exposed to corrosive environments. The average thermal coefficient of expansion of the Ce-ZTA composition between 25$1000^{\circ} \mathrm{C}$ was found to be $6.42 \times 10^{-6} \mathrm{~K}^{-}{ }^{1}$.

Because foam strengths are controlled by the flaws resent in the struts, it is imperative to minimizing flaw size and population density in order to achieve high strengths. Most flaws are present as impurities, agglomerates, air bubbles, or cracks. 
Thus, it is important to control and minimize the sources of potential flaws, by controlling the properties of the slurry, which in return, will be largely responsible for the fired foam properties. Many of the properties of the Ce-ZTA composition had been optimized in the previous programs, however, tailoring was still necessary to combine the major components of the proposed candle into a completed system.

\subsection{Foam Core Development}

The Selee ceramic foam is made by a replication process that involves the use of a thermoset polyurethane (PU) foam. The PU foam is impregnated with an aqueous slurry of ceramic particles, which is deposited on the PU foam webs. The foam cell size is regulated by the original cell size of the PU foam and by the firing shrinkage. The typical foam density is in the range $10-25 \%$ of theoretical density (TD). Excess slurry is removed through the use of rollers. By regulating the amount of slurry removed, the density of the foam is determined. A Ce-ZTA ceramic foam is shown in figures 1 and 2.

To prepare the foam core, polyurethane foam blanks were cut from 30ppi stock. These blanks measured 5 in $* 5$ in $* 14$ in. A hole was cored drilled lengthwise down the center of the blank so that a steel rod could be inserted. The foam was cut using a standard wood lathe. The rod was necessary in order to stabilize the foam during the process. A chisel was used to remove the excess foam and to attain the desired shape. A razor blade was used as a final effort to remove any loose struts. Although it was difficult to maintain exact tolerances, using this method it was possible to create a foam core with an integral flange and an end cap.

The foam was impregnated using standard Selee processes. A Ce-ZTA ceramic slurry with 10 volume percent ceria zirconia was used. The targeted density was $13 \%$ theoretical density. Higher density parts were also manufactured; however, the pressure drop of these parts was too great.

One of the major challenges to preparing parts that met the specified tolerances was drying the foam element without any deformation. Due to the odd shape of the flanged end, a system had to be devised which would allow the part to dry without having any weight on one particular side during the process. If the foam was allowed to dry laying on one side, the resulting shape would be severely out of spec. To dry the samples without deformation, it was necessary to dry each sample individually in a plaster mold. The plaster mold maintained the desired shape of the foam. The impregnated part was dried using a hand-held drier, being rotated constantly in order to maintain the cylindrical shape. 


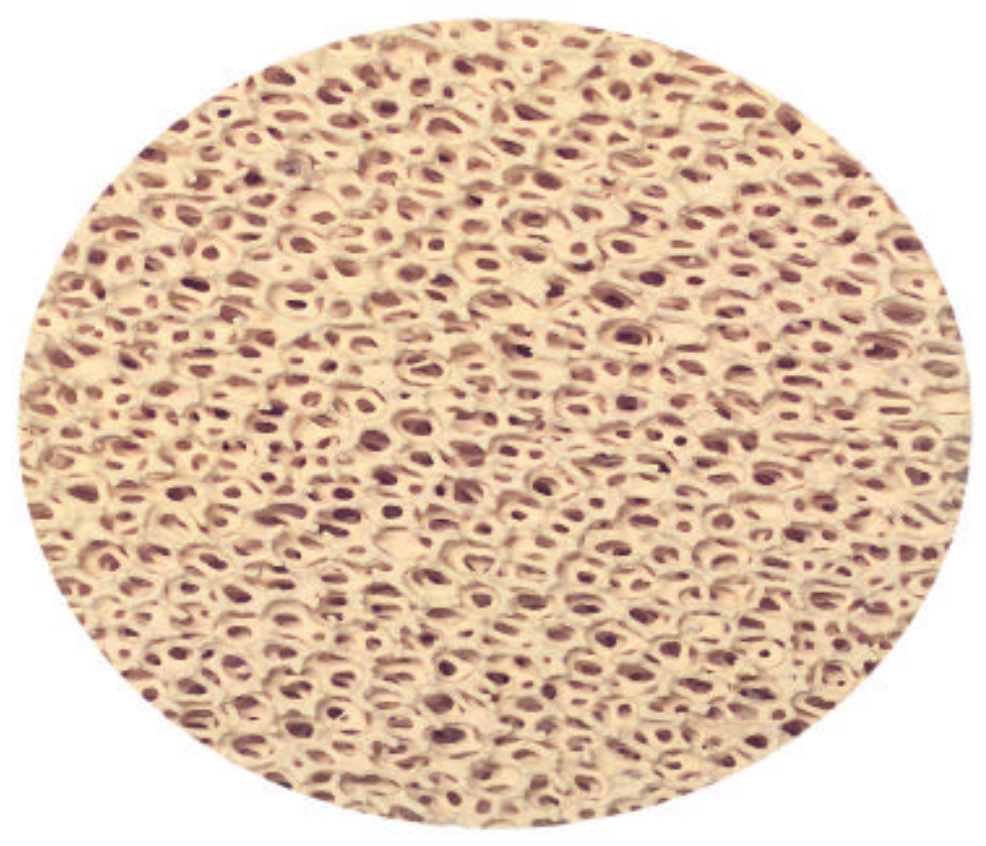

Fig.1. Ce-ZTA Ceramic Foam, 30 ppi.

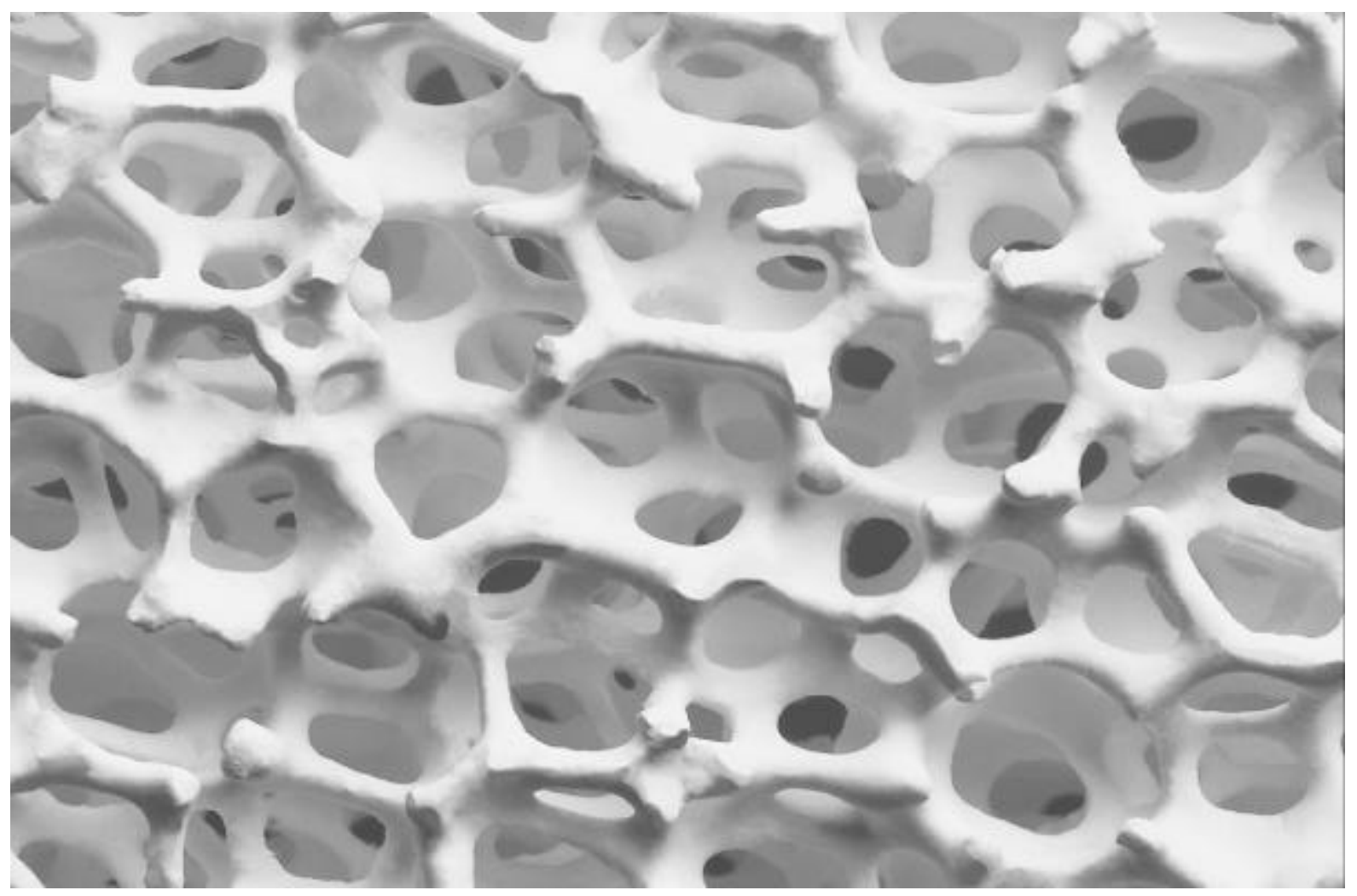

Fig. 2 Typical Selee Ceramic Foam, same as above. 


\subsection{Membrane Development}

The membrane composition was developed using the optimized Ce-ZTA slurry as a starting point. GPM technology which was developed at Selee Corp. is an alternative method to fabricating porous ceramics. Using this technology, organics were added to the Ce-ZTA composition in order to achieve the desired porosity. Several compositions with varying densities were tested for pressure drop and strength. The fired membrane exhibited cells of 100-150 microns with interconnecting windows of 10-20microns. The greatest obstacle to the development of a membrane was the tendency towards cracking during the firing and drying stages.

A composition was developed with a $20 \%$ theoretical density. This composition was used to prepare the final samples. Bars $(2.5 \mathrm{in} * 0.4 \mathrm{in} * 0.3 \mathrm{in})$ of this membrane composition were broken in a three-point bend test and yielded an average strength of 3500 (psi). Figure 3 shows a typical $20 \%$ theoretical density porous ceramic substrate.

Several attempts were made during the course of this program to form a castable coating into which a foam membrane could be inserted. One of the techniques which was investigated was using an extrusion process to form the outer membrane coating. A slipcast method involving the use of plaster molds was also investigated. These attempts were unsuccessful because the coating material was too thick, causing cracks during the drying and firing stages. As well, the thickness of the membrane is limited by the pressure drop requirements.

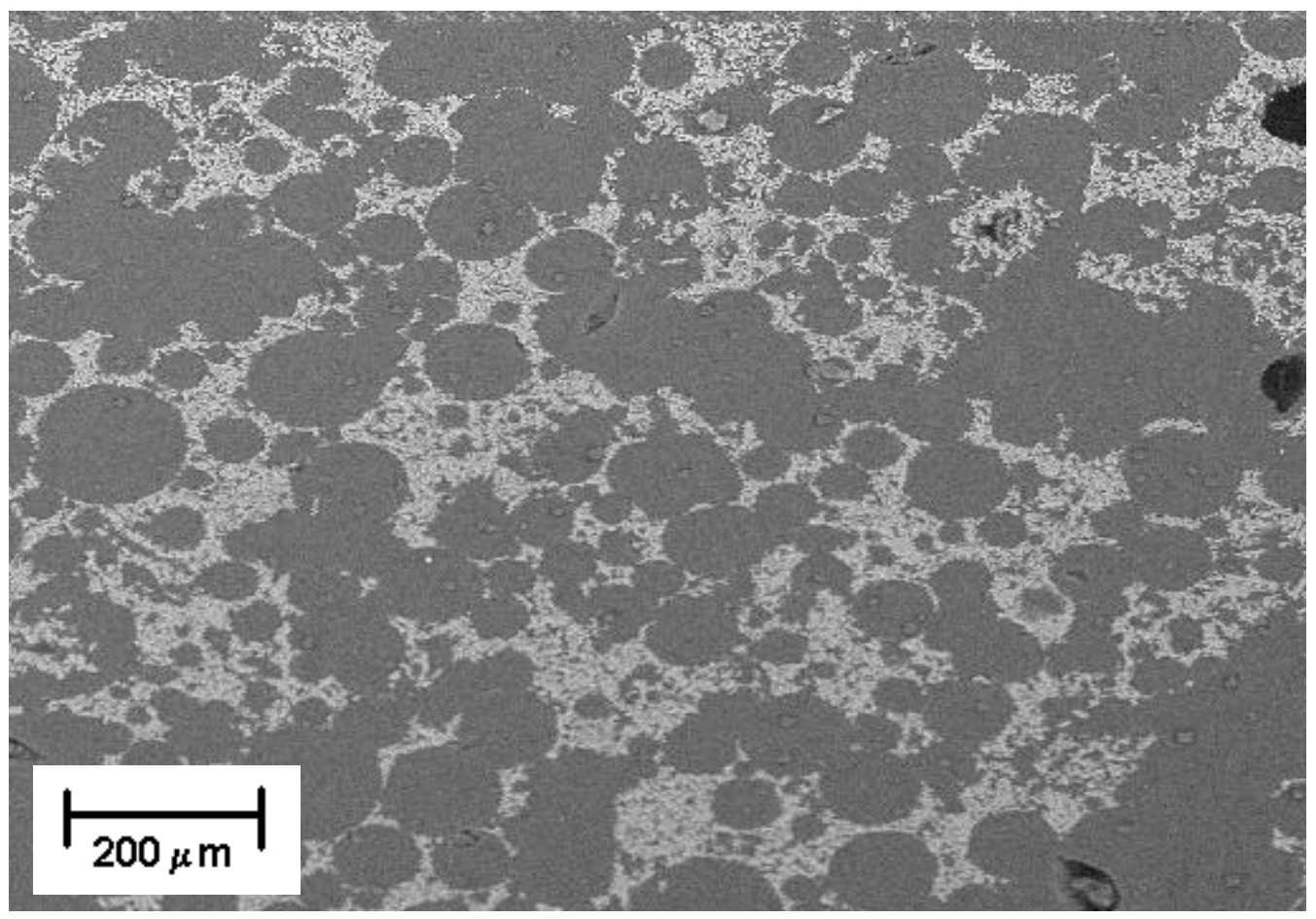

Figure 3. 20\%Theoretical Density Microporous Foam for Membrane Development. 


\subsection{Application of Membrane to Foam Core}

In order to attain the required pressure drop and to avoid any cracking, it was necessary to make a very thin coating. Brushing the coating on over the foam core created thick spots in the coating. This was because the coating filled in the cell voids. Besides augmenting the cracking problems, having these thicker spots also increased the pressure drop. Cornstarch was used to partially alleviate these problems. The cornstarch was rubbed into the reticulated foam, filling in the cell voids. This created a smooth finish upon which to apply the coating. The parts were lightly dusted with a dry brush to remove any excess cornstarch that may have kept the coating from bonding to the inner membrane. The coating was carefully brushed on in approximately $1 \mathrm{~mm}$ layers. This first coating was air dried; however, small cracks were visible. It seems these cracks were mainly due to drying difficulties due to thickness variation in the coating.

Sandpaper was used to smooth out the surface and then a second coating was applied. It was brushed on in the opposite direction of the first coating. It was thought that by doing so, the fibers would interlock, helping to eliminate any cracking during firing or drying. The second coat was dried at $300^{\circ} \mathrm{F}$. No cracking was visible after this second coat was applied. Again, the samples were sanded to obtain a smooth finish.

\subsection{Firing}

Although many different firing methods were investigated, it was determined the samples had to be fired standing up on the flanged end. The samples had a tendency to crack and warp when fired horizontally. Even when placed in firing blocks, which supported the entire length of the sample including the flanged end, the samples still had a tendency to warp severely. Because it was thought that the shrinking during firing was causing the warpage, green firing blocks were made. These green blocks were expected to shrink at the same rate as the samples, thus, eliminating problems. In order to decrease the effects of friction, fiber was placed between the samples and the firing blocks. This method also failed, the samples curved upwards during firing. Standing the samples up on their flanged end and then firing to a slightly lower temperature yielded better results. Much of the cracking was eliminated along with only a slight amount of warpage. A ceramic open-ended box was built so that bubbled alumina could be poured around the sample as it fired vertically. It was thought that if the entire length of the sample could be supported during firing, that no slumping would occur. Surprisingly, when the bubbled alumina was used to support the sample during firing, the warpage was even more dramatic and crazing was present on the surface. The reasons for this are unknown.

The following firing procedure was chosen for the delivered samples:

1) The parts were fired standing on end throughout the firing program.

2) The parts were pre-fired in a gas furnace with high excess air to $1000^{\circ} \mathrm{C}$. The parts were fired at a rate of $100^{\circ} / \mathrm{hr}$. Firing to this temperature allowed for the slow 
volitization of organics and the polyurethane foam. It also allowed for the repair of minor cracks and holes left from the volitization.

3) Finally, the samples were sintered at $1500^{\circ} \mathrm{C}$ for 30 minutes with a ramp up time of ten hours. The soak time had been reduced from an original soak time of four hours in an effort to reduce slumping.

\subsection{Pressure Drop Testing}

A pressure drop apparatus was set up in order to test the pressure drop of each of the prototype samples. The apparatus consisted of several pressure drop gauges and a Brooks flow meter. The maximum allowable pressure drop was given as $6+/-2$ mbar at $52 \mathrm{~m}^{3} / \mathrm{hr} /$ candle. The given flow rate, when calculated for a smaller prototype sample, is the equivalent to $184 \mathrm{~L} / \mathrm{min} /$ prototype candle.

\section{Characterization of Delivered Samples}

Table 1. describes the dimensions and pressure drop measurements of the delivered samples.

Strength measurements were taken by sawing the finished candles into cylinders. These cylinders were placed horizontally on a flat plate and crushed at room temperature using an Instron Universal tester. The cross-head speed was set at $0.1 \mathrm{~cm} / \mathrm{min}$. A total of five samples were broken. These samples did not have an open core. Table 2. shows the amount of force which was required to crush the cylinders.

The specified dimensions for candle filters with an inner core and without are given in Figures 4 and 5.

Figure 6. shows an image of one of the delivered samples that was fabricated. 
Candle Filter

Foam Core

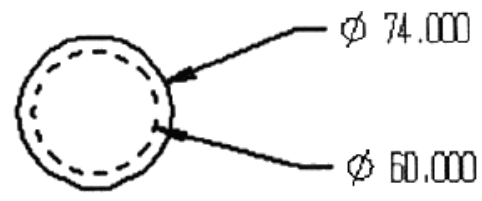

With Outer

Membrane

Figure 4

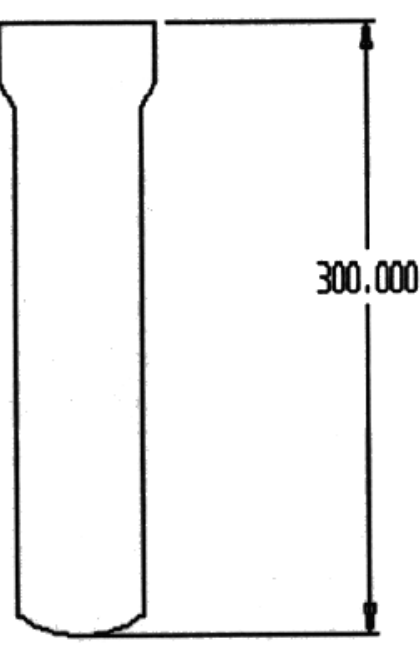

Candle Filter

Foam Core

With Outer

Membrane

And Inner Bore

Figure 5
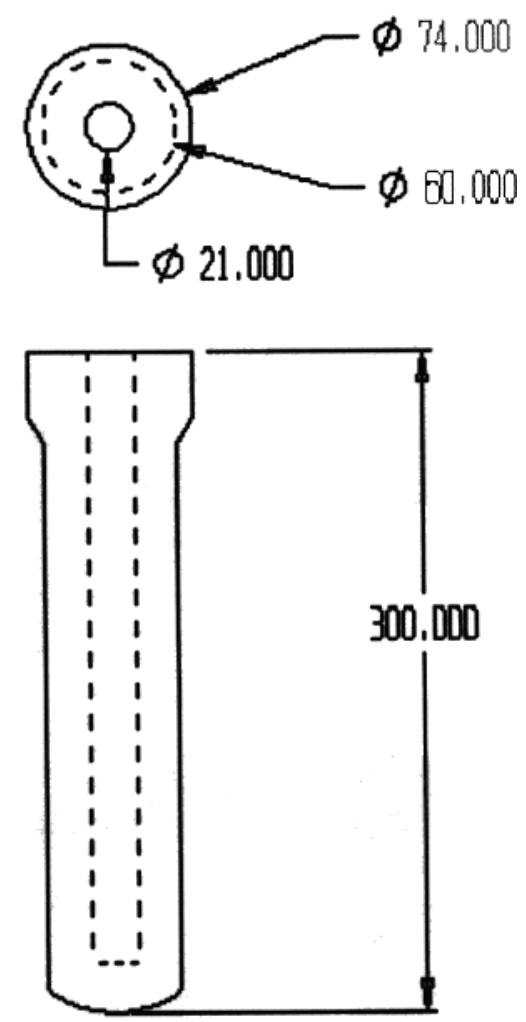
Table 1. Tolerances: Measured and Specified for Delivered Samples

\begin{tabular}{|c|c|c|c|c|c|c|c|}
\hline $\begin{array}{c}\text { Sample } \\
\text { ID }\end{array}$ & $\begin{array}{c}\text { Tube } \\
\text { Diameter } \\
(\mathbf{m m})\end{array}$ & $\begin{array}{c}\text { Flange } \\
\text { Diameter } \\
(\mathbf{m m})\end{array}$ & $\begin{array}{c}\text { Candle } \\
\text { Length } \\
\text { Diameter }\end{array}$ & $\begin{array}{c}\text { End Cap } \\
\text { to Start of } \\
\text { Flange }\end{array}$ & $\begin{array}{c}\text { Tube } \\
\text { Length } \\
(\mathbf{m m})\end{array}$ & $\begin{array}{c}\text { Inner } \\
\text { Core } \\
\text { Diameter }\end{array}$ & $\begin{array}{c}\text { Pressure } \\
\text { drop } \\
(\mathbf{m b a r})\end{array}$ \\
\hline $\begin{array}{c}\text { Specified } \\
\text { Tolerance }\end{array}$ & $60+/-1 \mathrm{~mm}$ & $74+/-1 \mathrm{~mm}$ & $27+/-1 \mathrm{~mm}$ & $15+/-1 \mathrm{~mm}$ & N/A & $\begin{array}{c}\text { Vendor } \\
\text { Dependent }\end{array}$ & $\begin{array}{c}6+/-2 \mathrm{mbar} \\
@ 11 \mathrm{~m}^{3} / \mathrm{hr} / \\
\text { sample }\end{array}$ \\
\hline \hline 50012 & 60.06 & 75.52 & 26.0 & 15.8 & 301 & $\mathrm{n} / \mathrm{a}$ & 10.0 \\
\hline 50013 & 60.05 & 75.01 & 27.1 & 17.7 & 302 & $\mathrm{n} / \mathrm{a}$ & 7.5 \\
\hline 50014 & 59.40 & 75.39 & 28.0 & 17.0 & 302 & $\mathrm{n} / \mathrm{a}$ & 10.0 \\
\hline 50015 & 61.88 & 74.91 & 28.4 & 18.1 & 304 & 21.4 & 7.5 \\
\hline 50016 & 63.13 & 76.17 & 28.9 & 18.9 & 304 & 21.0 & 8.7 \\
\hline 50017 & 61.50 & 76.47 & 27.4 & 17.5 & 303 & 21.0 & 8.7 \\
\hline
\end{tabular}

Notes: The specified tolerance for the flow rate was given per (actual size) candle. The flow rate was adjusted for the smaller prototype samples. The measured pressure drop data is given per prototype candle.

Table 2. Radial Crushing Strength

\begin{tabular}{|l|l|l|l|}
\hline Sample ID & Diameter(mm) & Length(mm) & Load (psi) \\
\hline $50602 \mathrm{a}$ & 62.57 & 113.80 & 255.8 \\
\hline $50602 \mathrm{~b}$ & 61.79 & 110.98 & 249.5 \\
\hline $50602 \mathrm{c}$ & 61.46 & 118.61 & 201.3 \\
\hline $50603 \mathrm{a}$ & 61.53 & 111.98 & 233.4 \\
\hline $50604 \mathrm{~b}$ & 62.01 & 112.52 & 256.2 \\
\hline
\end{tabular}

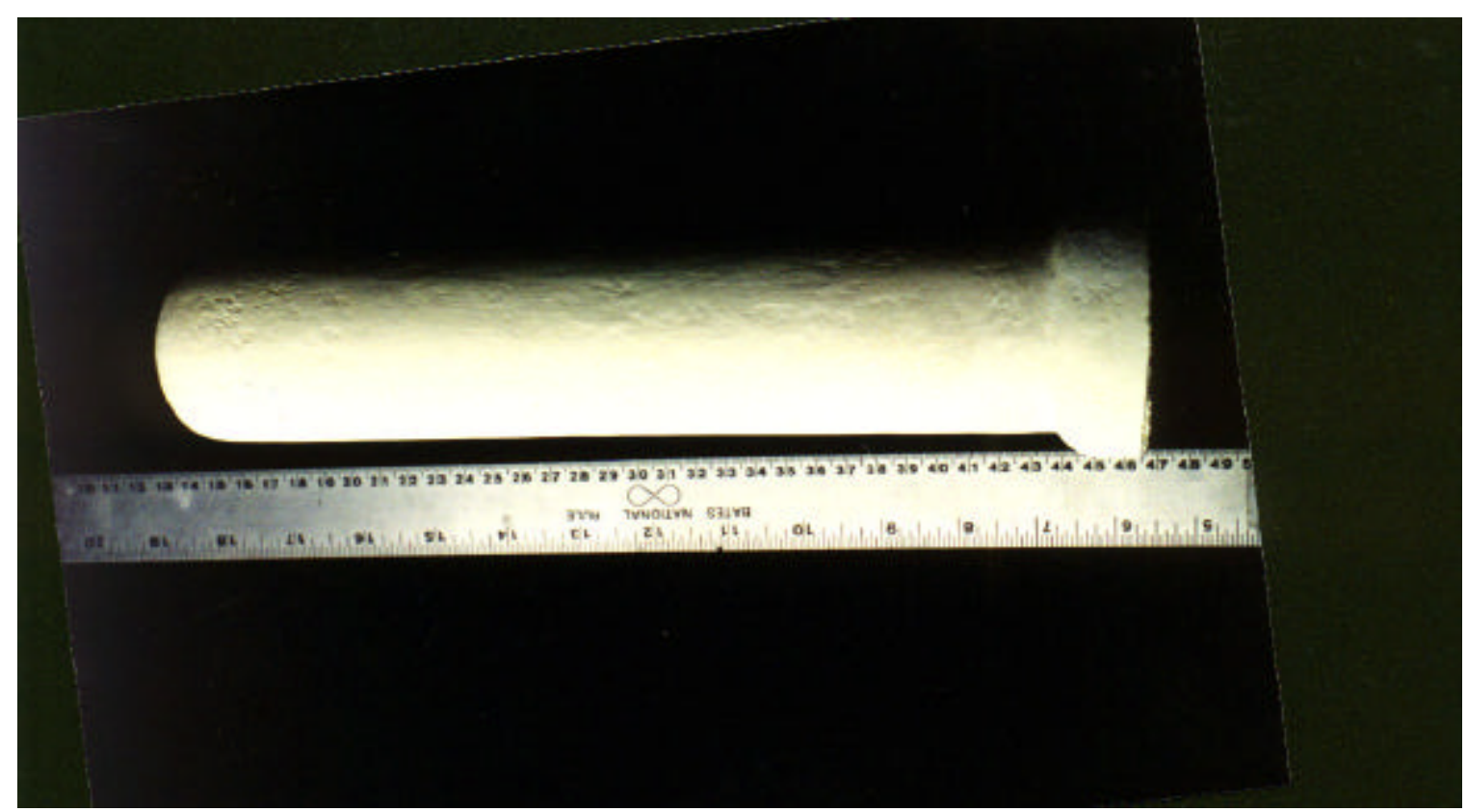

Figure 4. Candle filter consisting of open-cell foam core (Selee technology) and ceramic membrane (GPM technology). 


\section{Conclusions and Suggestions for Future Work}

Although six prototype samples were fabricated which met most of the requirements, it was obvious that the approach utilized to produce these subscale prototype parts would not be a practical method for producing 1 meter long (actual size) candles. Several steps in the process would be difficult to perform on a larger scale. It is concluded that in order to produce a larger candle the following procedures would need to be investigated:

1) The porosity and/or pore size of the GPM layer should be increased to lower the pressure drop. By doing so, it is likely that a castable/extrudable coating could be realized. The foam core could then be inserted into the casting. A thin microporous membrane, such as was utilized in this program, could then be either dipped or brushed onto the outer surface of the castable "inner coating". This would allow for much more control over the dimensions and the pressure drop. It would also eliminate many difficulties in the drying process.

2) An improved firing technique is needed. The part must be supported and heated evenly to prevent warpage or slumping during drying and firing. 


\section{References}

1. Novel High Strength Ceria-Zirconia Toughened Alumina Ceramic with Superior High Temperature Corrosion and Erosion Resistance.

Instrument No. DE-FG05-94ER81859 